\title{
Enhancing Cross-cultural Competence in \\ Multicultural Teacher Education: Transformation in Global Learning
}

\author{
Vilma Seeberg \\ Theresa Minick \\ Kent State University
}

U. S. A.

Teacher education needs to engage teacher candidates in developing crosscultural competence so that they may be able to transmit global learning to their future students. This study theorizes cross-cultural competence (CCC) from the perspectives of multicultural and global education. During a four-year project at a mid-western US university, utilizing Web 2.0 technologies, the authors implemented and evaluated a pedagogical approach intended to foster crosscultural competence with an emphasis on dispositional transformation. A mixedmethod design assessed students on CCC standards and found that they developed affective as well as cognitive CCC. By implication, the model can be adapted in other teacher education classrooms to foster cross-cultural, multicultural global learning.

\author{
Significance and Purpose of the Study \\ Cross-Cultural Competence \\ Cross-Cultural Competence Approach Projects \\ Method \\ Findings and Evaluation of Students' Cross-Cultural Competence \\ Conclusion \\ Notes \\ Acknowledgments \\ References
}

As the world population exceeds seven billion, distances shrink, and people move in greater numbers across national borders, teacher educators are asked to prepare teachers who are competent in helping learners function in a globalizing reality. To this end, teachers are expected to possess the knowledge, dispositions, and skills to engage students with the globalizing world (American Council on Education, 2006) and to do so in a transformative way. By transformative, in this context, we mean students making discoveries while experiencing a cross-cultural encounter rather than acquiring information "about" others in a predominantly cognitive and abstract way (Cushner \& Brennan, 2007, p. 3). Scholars and organizations associated with teacher education agree that cross-cultural dispositions and change-agent skills needed by teachers for global 
learning cannot be gained abstractly: "Global citizenship cannot be achieved by merely learning things in a traditional classroom experience, but rather requires active engagement with the world" (American Council on Education, 2006, p.16; see also Association of American Colleges and Universities, 1999; Mansilla \& Jackson, 2011; Sperandio, Grudzinski-Hall, \& Stewart-Gambino, 2010). In the authors' experience as instructors of core teacher education courses, however, socio-historical and socio-cultural knowledge of a multicultural globalizing world continues, despite transformative rhetoric, to be conveyed in traditional ways. Global learning is taught as an intellectual exercise, relying on course readings, for example, and has not been approached as a transformative exercise.

Because of our experience, we challenged ourselves to develop a global learning project that would contribute to multicultural and cross-cultural global education in our core teacher education courses. We wanted to engage teacher candidates actively, both affectively and cognitively, in diversity and in interaction with others in global contexts by involving them in direct experiences, rather than learning "about" them. We also recognized the difficulty of evaluating the crosscultural competence outcomes of teacher candidates in these kinds of projects. In campus-based teacher education programs like ours, creating situations to engage students in direct cross-cultural competence (CCC) experiences implies many obstacles: little diversity among students in classes, the short semester timeframe, and the inability of students to participate in study-abroad programs, due to work schedules and lack of resources. At Midwestern US University (MWU), where we teach, our students did not appear to be ideal targets for multicultural, cross-cultural global learning projects. They frequently lacked multicultural experiences and the personal motivation or social need to know the other. The majority of our students came from encapsulated middle class families who had raised them in racially and otherwise culturally isolated White communities, to which the students often intended to return.

Therefore, we proceeded in our core teacher education courses, over many terms, to develop and integrate experiential learning of CCC with the use of computer-mediated communication (CMC) Web 2.0 tools, including videoconferencing. We developed the approach in 10 sections of core teacher education courses over four years. Throughout this time, we explored how students manifested cultural competence and how it could be assessed ${ }^{2}$. After reviewing the extensive literature across several disciplines, we formulated a set of standards of CCC to assess the teacher candidates' performances. We used CCC standards in developing the instructional approach and the evaluation of learner outcomes, the cross-cultural competence approach (CCCA), which we explore in this study.

\section{Significance and Purpose of the Study}

The significance of $\mathrm{CCC}$ for teacher candidates lies in its transgenerational impact. The next generations of youth increasingly have to 
master critical $21^{\text {st }}$ century skill sets which include global awareness (Stewart, 2007) and competence (Jackson, 2009; Scarboro, 2012; Sperandio et al., 2010). It takes a cross-culturally competent teacher to diversify classroom experiences to include global dimensions and engage students in cross-cultural experiences (Diller \& Moule, 2005). These authors postulate that, as teacher candidates progress through a reflective cross-cultural development process, they will experience a transformation of perspective from ethnocentric to ethno-relative (Bennett, 1993) and thus learn to guide their future students through similar processes

The purpose of this study ${ }^{1}$ was to explore whether and how the CCCA improves teacher candidates' affective and cognitive CCC in a one-semester course. The project's major guiding questions were:

1. In what ways, if any, does the CCCA facilitate teacher candidates' CCC development in one semester?

2. In what ways, if any, does it affect their desire to take CCC into their future teaching?

3. In what ways, if any, does the thematic content of the different CCCA projects variously impact teacher candidates' CCC development?

There is a need to explore these questions empirically as there is a dearth of such studies. Laughlin and Nganga (2008) provided one of the few empirical studies on the effectiveness of using a cross-cultural approach in an upper division education courses on rural pre-service teacher dispositions, skills, and knowledge. The present study is conducted among exurb and small town participants; these form the majority of teacher candidates across the United States.

\section{Cross-cultural Competence: A Review of the Literature}

In teacher education, awareness of the need for global CCC grew along with scholarship in multiculturalism and intercultural communication in curriculum and instruction. In order to answer our guiding questions and assess teacher candidates' CCC development, we used interdisciplinary literature to develop CCC conceptually so that we could develop an authentic assessment tool (see Newman \& Wehlage, 1993). The literature of the interdisciplinary fields of multicultural and intercultural education over the past 30 years developed the foundational concepts of cross-cultural competence.

Multicultural education scholars like Delpit (1988), Banks (1988, 2004), Sleeter (1991), Sleeter and Grant (1987), Nieto (2000), Hollins (1999), DermanSparks and Phillips (1997) all argued that to be transformative, multi- and crosscultural pedagogy must first affect teacher's dispositions to act proactively (Sleeter, 1991) and that it must be culturally relevant and socially reconstructive. Gay (2000) and Ladson-Billings (1995) wrote highly acclaimed works on culturally responsive instruction focused on specific cultural elements. Scholars 
in counseling explored racial identity formation, particularly Cross, Strauss, and Fhagen-Smith (1999), Helms (1997), and Phinney (1992) ${ }^{2}$. All of these themes have contributed to the conceptual development of CCC.

In the global education fields, some of the early scholars of teaching approaches were Hanvey (1975), who is often considered the father of modern global education, Gudykunst and Kim (1984), Casteel (1976), Brislin, Cushner, Cherrie, and Yong (1986), and Ponterotto and Pederson (1993). Intercultural sensitivity scholars like Bennett and Bennett (2004; see also Bennett, 2009) created an intercultural learning and intercultural development index. Fiske and Taylor (1992) explored the affective-cognitive structures of intercultural development. Merrifield $(2001,2005)$ and Merrifield, Lo, Sum, and Kasai (2008) have been pioneers in globally oriented program design that combines cognitive (e.g., knowledge of the worlds of others) and affective (e.g., prejudice reduction, development of open-mindedness) elements. Her work draws together common elements of multicultural and global teacher education. Similarly, Villegas and Lucas (2002) suggest that teachers need appropriate dispositions to become culturally responsive educators. Together these works provided the foundational constructs of cross-cultural competence and contributed to the publication of the Handbook for Advancing Comprehensive Internationalization's CCC model by American Council on Education' (2006).

The above conceptual literature provided us with the common core of descriptors for our CCC; however, we wanted to triangulate our concepts against a validated instrument in order to establish internal concept validity. Kelley and Meyers' (1987, 1989, 1992, 1995) Cross-Cultural Adaptability Inventory (CCAI), was such a validated instrument, widely used in cross-cultural projects. The CCAI measures underlying psychological dimensions of cross-cultural dispositions and effectiveness. The CCAI dimensions will be elucidated below as we triangulate them with our own CCC standards.

\section{Cross-Cultural Competence Standards}

As stated above, drawing from the multi-disciplinary literature reviewed, we developed the Four CCC Standards for assessing our teacher candidates from largely mono-cultural backgrounds. The standards used in our project follow.

CCC standard 1: Strengthened cultural consciousness and positive cultural identity development (Cross et al.,1999; Helms, 1997; Hollins, 1999). This includes behaviors relating to the self, such as reflecting on one's cultural influences and environments in order to understand own beliefs and values (Kelley \& Meyers, 1987).

CCC standard 2: Positive intergroup contact and reduction of prejudice (Allport, 1979; Derman-Sparks \& Brunson Phillips, 1997; Ponteratto \& Pederson, 1993). This includes behaviors relating to the other, such as 
comparing values and beliefs, reconsidering one's prejudices, expressing an interest to continue learning about others. Merrifield (2005) uses the term worldmindedness.

CCC standard 3: Acceptance, respect for and appreciation of the other who is culturally different from the self (Bennet, 1999; Burbules \& Rice, 2000). This includes affective changes in behavior, such as gaining knowledge, insight, and understanding of cultural differences and accepting the world of the other (Bennett \& Bennett, 2004; Reimers, 2009), including "acknowledging the recognition or awareness on the part of the individual that he or she has a view of the world that is not universally shared" (Hanvey, 1976, p. 3).

CCC standard 4: A perspective that is anti-racist, anti-sexist, antiimperialist and pro-social justice action (Derman-Sparks \& Brunson Phillips, 1997; Gay, 2001; Sleeter, 1991). This includes behaviors that signify a commitment to furthering intercultural contact and multicultural communities, gaining skills to negotiate cultural conflicts. Using their Global Perspectives Inventory, Braskamp, Braskamp, and Merrill (2010) found that most people who see themselves as global citizens want to work for the rights of others. This standard directly addresses the changeagent skills that affirm voice and active democratic practices.

These competence standards are not gained in a linear fashion, although they do build on each other recursively. They do not indicate stages or levels per se, but rather a growth pattern that may be interdependent (Bennett \& Bennett, 2004).

Table 1. Comparison of Cross-cultural Competence Standards and the CCAI Instrument

\begin{tabular}{|l|c|c|c|c|}
\hline $\begin{array}{l}\text { Comparison of CCC } \\
\text { Model }\end{array}$ & \multicolumn{3}{|c|}{ Cross-Cultural Adaptability Inventory (CCAI) } \\
Dimensions \\
\hline Four Standards of CCC & $\begin{array}{c}(1) \\
\text { Flexibility, } \\
\text { Openness }\end{array}$ & $\begin{array}{c}(2) \\
\text { Emotional } \\
\text { Resilience }\end{array}$ & $\begin{array}{c}\text { (3) } \\
\text { Perceptual } \\
\text { Acuity }\end{array}$ & $\begin{array}{c}\text { (4) } \\
\text { Personal } \\
\text { Autonomy }\end{array}$ \\
\hline $\begin{array}{c}\text { 1) Strengthened Cultural } \\
\text { Consciousness and } \\
\text { Positive Cultural Identity }\end{array}$ & $\bullet$ & $\bullet$ & & $\bullet$ \\
\hline $\begin{array}{c}\text { 2) Positive Intergroup Contact, } \\
\text { Reduced Prejudice }\end{array}$ & $\bullet$ & $\bullet$ & & $\bullet$ \\
\hline $\begin{array}{l}\text { 3) Acceptance, Respect for } \\
\text { and Appreciation of Cultural } \\
\text { Diversity }\end{array}$ & $\bullet$ & $\bullet$ & $\bullet$ & $\bullet$ \\
\hline $\begin{array}{l}\text { 4) Perspective That Is Pro- } \\
\text { Social Justice Action }\end{array}$ & & & & $\bullet$ \\
\hline
\end{tabular}


To establish construct validity of the CCC standards, as mentioned above, we evaluated them using the CCAI underlying dimensions of adaptability (see Table 1). CCC Standard 1, Cultural Self-Awareness and Positive Cultural Identity, corresponds with CCAI dimensions (2) emotional resilience and (4) personal autonomy. CCC Standard 2, Reduced Prejudice, corresponds with CCAl dimensions (1) flexibility, openness, (2) emotional resilience, and (4) personal autonomy. CCC Standard 3, Acceptance, Respect for and Appreciation of Cultural Diversity, corresponds with CCAI dimensions (1) flexibility, openness, (2) emotional resilience, and (3) perceptual acuity. CCC Standard 4, Perspective that is Pro-Social Justice, corresponds to CCAI dimension (4) personal autonomy. For us, confidence in the construct validity of the CCC standards was established through the strong correspondence we discerned with the CCAI.

\section{Cross-cultural Competence Approach}

Our purpose with the CCCA was to challenge teacher candidates' abilities to interact and cross social boundaries. In order to provide this challenge, we set up experiential learning opportunities via CMC tools that provided direct contact with others (Burbules, 2000). It was our goal that contact with others would require students to develop critical thinking skills, which are an essential element of transformative learning (Jonassen, 2000). As Fulton and Riel (1999) and Harris (2000) suggest, the attempt was to build communities of practice across geographic and cultural distance by various CMC formats. These communitybuilding opportunities would culminate in videoconferences (Scardamalia, Bereiter, \& Lamon, 1994). Inspiration came from projects such as the Global Schoolhouse, the University of Missouri-Columbia College of Education's Global Initiative, and projects by the Friendship through Education Consortium (described in more detail in Jonassen, Hjowland, Moore, \& Marra, 2003, pp. 98100). What all these projects have in common with ours is their purpose to provide experiential learning opportunities with cross-cultural partners.

\section{Cross-cultural Competence Approach Projects}

Over the four years of this study, the CCCA was applied to several different kinds of cross-cultural experiential learning projects. The projects were generally organized according to the following format: using a cross-cultural inquiry-based topic mutually determined with the cross-cultural partner, both sets of students would do substantial preparatory research, share information and ideas online, and hold a discussion in a real-time video conference ${ }^{3}$. Throughout the process, we, as author-instructors, conducted oral debriefings in the classroom and collected written final reflections. The student-led inquiry approach allowed for many organic turns and twists in each project as will be described in the projects below. 
In this article, in order to find an answer to guiding question 3: "In what ways, if any, does the thematic content of the different CCCA projects variously impact teacher candidates' CCC development," we review findings in terms of three projects: 1) Bias in History Textbooks: The Alamo, 2) Comparing Service Learning/Volunteerism: Citizenship Education, and 3) Native American Schooling at the Comanche Nation College.

\section{Bias in History Textbooks: The Alamo}

The Bias in History Textbook project content focused on a famous historical conflict between Mexico and the United States, the Battle of the Alamo, which would bring together students of very different perspectives. As earlier described, our MWU students were predominantly White suburban and exurban. They were partnered with culturally- and linguistically-different students who attended a private international high school in Mexico City. Both sets of students researched how school textbooks presented the same historical event and reflected on how it had shaped their own view of the event and their current attitudes toward the other nation. After several weeks of computer-assisted research and online communication that established the deliberation topics, a lively videoconference was conducted. After this, MWU students conducted an oral debriefing and wrote reflections submitted within the week.

\section{Service Learning/Volunteerism: Citizenship Education}

The Citizenship Education Project took place a year after the Battle of the Alamo project. Its content focused on community service as part of the high school experience of two sets of students: MWU students and a different class of the Mexican private high school. These students compared their experiences and their perspectives by videoconferencing. MWU students followed up as they had before in the Alamo project.

\section{Native American Schooling: Comanche Nation College}

The Comanche Nation College Project required MWU students to cross, based on their reflective comments, what we perceived to be one of the greatest cultural gaps in the Americas The project was designed to be knowledge-heavy, with MWU students, as novice learners, investigating the current status and history of Native American education. The president, academic provost and students of the Comanche Nation College, through videoconferencing, presented on education at Comanche Nation College and in their communities, as well as on Comanche cultures and traditions. This was followed by a cross-cultural dialogue for which MWU students had prepared interview questions. MWU students spent considerable time debriefing the conversations and reflecting 
critically on their own prior lack of knowledge and preconceived notions about Native Americans. They followed up, as they had in the previous two projects, with written reflections.

\section{Method}

To assess how students were meeting the four CCC standards during the implementation of the CCCA in the teacher education courses', we observed the students as they discussed the projects and in their other collaborations with their cross-cultural partners. We also read, took field notes, and discussed the CMC records, such as emails, discussion boards, video-conferences, and the oral debriefings. The written reflections were analyzed within a few weeks after the end of each CCCA project, during the same semester.

As mentioned above, a set of CCC standards was generated in a reiterative analysis using the literature, fieldwork notes, and students' work. A draft was developed during fieldwork and continued to be refined through final coding in the concluding analysis phase of the study.

In the analysis phase, Barone and Eisner's (2006) notion of the thematic guided the act of finding and locating the general in the particular. The data were examined for emerging themes until they reached redundancy and saturation. Emerged themes were organized into categories and subcategories until a point of clarity and agreement between the two authors was reached. After this posthoc process, the emerged themes were checked against the drafted CCC standards. We found they were consistently in alignment, as will be shown in the findings of the study.

\section{Participants}

The participants in this study were teacher candidates at MWU. They were enrolled in social foundations and methods courses. Over a period of four years, CCAI and supporting qualitative data were collected for a data set obtained from 11 classes. For this article, we report on data collected from three classes in social foundations of education, including 75 students that used the three experiential learning projects. Disaggregated data analysis for the classes showed no significant differences in the findings on either the quantitative or qualitative data sets, which confirmed that the sample selection from the larger data set is not a limitation of the study.

Participants in our research reflect the typical enrollment in teacher education courses in the United States in the first decade of the $21^{\text {st }}$ century. With average enrollment of 23-25 students, there were mostly White females, three to six White males, and one or two Black females per section per term. Pre-semester oral surveys of students showed that few students in all the classes (the larger data set) and none of the participants had any previous 
experience in diverse communities; all but the few students of color had grown up in predominantly White middle-class neighborhoods and had not met with much cultural diversity in their college classrooms. Most White students had known one or two persons of color in their high school, and some students had traveled internationally, usually briefly to tourist destinations. The students in the partner schools were not participants in this study.

\section{Findings and Evaluation of Students' Cross-cultural Competence}

In this section the findings on student responses to the CCCA are presented, focusing on the results from the qualitative instrument CCAI and student voice.

\section{Findings on the Quantitative Instrument CCAI}

The use of the CCAI was originally designed to establish a psychological basis for the CCC standards. In addition, it became clear from field notes and inclass observation that administering the CCAl at the beginning of the actual projects helped students express their learning from the cross-cultural experiences more concretely. They frequently used language reminiscent of the CCAI dimensions; for example, they described their responses as being open to others or as having learned desirable behaviors (such as those named in the CCAI).

Students' scores on the CCAI provided some interesting results. Students scored surprisingly high on the dimension of flexibility/openness, with an average score in the 9th stanine. However, on the other dimensions, concern and emotional resilience $\left(2^{\text {nd }}\right.$ stanine $)$, perceptual acuity $\left(4^{\text {th }}\right.$ stanine $)$, and personal autonomy ( $5^{\text {th }}$ stanine), the average score was much lower. On these three dimensions the scores may indicate a lack of preparation for cross-cultural experiences; nevertheless, the high score on the dimension of flexibility calls for an explanation. Flexibility and openness are characteristics that are expected in this post-Civil Rights era and are often praised in MWU's diversity-conscious teacher education program. It would be reasonable for teacher candidates to want to see themselves as open.

For this reason, we understand that this does not mean that the participant teacher candidates were, in fact, open and flexible regarding cross-cultural experiences. Bennett and Bennett's (2004) Developmental Model of Intercultural Sensitivity and Helms' (1997) and Cross et al.'s (1999) racial identity development research found that, prior to contact, cross-cultural awareness is minimal; hence, students have little context for evaluating their flexibility regarding cross-cultural matters. Our students' high self-assessment likely reflects the common problem in socially sensitive self-report data, a phenomenon that has also been encountered in other undergraduate globalization programs 
(Sperandio et al., 2010). As a result, we wanted instead to use an authentic assessment method to directly assess the students' behavior in the process of practicing cross-cultural competence. Hence we developed the above described CCC standards.

\section{Findings on Student Voice}

The qualitative findings were derived from students' recorded CMC data and written reflections, as well as our own field notes.

Findings on the technology-enhanced aspects of the three projects. Web 2.0 technologies, videoconferencing, and other CMC tools provided the opportunity for sustained engagement and extended dialogue. In the Alamo project the students experienced extended sharing in virtual spaces with students in another country and culture. During debriefings and in reflections, deep questions arose spontaneously: How should history be recorded? How should it be taught? Can/do young people accept contrasting simultaneous positions on an historical event, i.e., both Mexico's and the United States'? We found this to illustrate students practicing CCC Standard 2, Positive Intergroup Contact, and movement toward meeting CCC Standard 3, Building Respect for Cultural Diversity.

In the online collaborations of the Citizenship project, the students in their respective country groups clarified their definitions of community service, service learning, and volunteerism, partially meeting CCC Standard 1, Seeking Knowledge to Strengthen Cultural Consciousness. After a few exchanges, enough trust had developed for the Mexican students to interject a question, "What is your opinion about Hispanic and Latin American people? -- How do you think we live?" MWU teacher candidates responded by asking the same question back. Both sides acknowledged that negative stereotypes abounded. Mexican students volunteered caricatures of Mexicans they believed were held by Americans. MWU students, however, were not equally explicit. The use of the term "American" came under heavy discussion by the Mexican students who challenged MWU students for reserving it to represent US nationals rather than all residents of the Americas. MWU teacher candidates wrote that they felt the Mexican students had a stronger cultural consciousness and positive cultural identity than they had themselves. We found this to be evidence of their meeting CCC Standard 1, Strengthening Cultural Consciousness and Identity, and CCC Standard 2, Positive Intergroup Contact, and partially meeting CCC Standard 3, Building Respect for Cultural Diversity.

These findings show that the direct communication between partners provided moments of reflection in which MWU students were challenged to clarify their definitions of concepts integrating personal doubts and perspectives, while continuing to develop trust with communication partners. According to our 
observations, we used this to mean that CCC Standards 1 and 2 were met by teacher candidates and Standards 3 and 4 were partially met.

Student reflections on the three projects. Students' written reflections on the direct and sustained interactions with others gave us the most concrete and independent data to analyze their work in developing CCC.

The Alamo Project. The students' written reflections on the Alamo history textbook project evidenced themes that closely corresponded with CCC Standard 2 and CCC Standard 3 and supported CCC Standard 1 and CCC Standard 4.

CCC standard 2, Positive Inter-Group Communication and Reduced Prejudice, was met when MWU teacher candidates commented that Mexican students were better educated than they expected and perhaps better educated than they themselves were. The following quotes exemplify our students' discovery:

"Our history books are written very biased in our favor while theirs are not. My attitude about the Alamo has become less biased in that I got to see another point of view from them. They showed that there really are two sides."

"Through this project I have learned that there is a huge difference between how we were taught and how Mexican students are taught about the Alamo."

CCC Standard 3, Acceptance, Respect for and Appreciation of Cultural Diversity, was met when MWU students wrote that Mexican students exhibited greater acceptance of the "American" point of view as represented in the texbooks than they themselves did:

"I learned that in Mexico they are taught to accept other countries' ideas and perspectives as correct to those people."

"I have learned from the students in Mexico that you do not have to be culturally biased when it comes to history. We can each hold our own views and opinions, but also be very open."

CCC Standard 1, Cultural Self-Awareness and Positive Cultural Identity, was met when MWU teacher candidates recognized a nationalistic bias. As students wrote:

"I was not aware how different our schools discuss the Alamo, e.g., in U.S. textbooks Santa Anna is a villain; in Mexican textbooks there is no villain or hero."

"Schools try to reinforce the power of America and how it has never done anything wrong...My attitude has changed."

CCC Standard 4, A Perspective that is Pro-Social Justice, was met as students concluded in their own voices: 
"I found that I preferred the Mexican way of teaching. The students gain more respect and understanding for the other culture."

"I think we need to take a closer look at our history books and represent both sides of the things that happened."

"I feel that with any type of history, our schools should teach it from all perspectives, not by bias to our own."

The MWU teacher candidates showed surprisingly critical self-reflection. They became aware of having accepted their American education without reflection. They also came to find validity in other and contradictory perspectives. Students resolved the psychological dissonance by suggesting ways that they as teachers could help future generations escape their cultural encapsulation. Students were developing, not only cognitively, but, more importantly, affectively. They illustrated improvement in their CCC by meeting the 4 Standards.

Community Service Project. At the outset of the project, MWU teacher candidates were asked in an unstructured pre-survey to articulate any stereotypes and preconceptions about Mexican students and their environment. Students exhibited a high level of misconceptions and stereotypes. Some of these were ideas such as writing that schools that Mexicans attend are "run down," and Mexicans "speak poor English," "live in poverty," "are lazy," "do field work," "are not as educated," and "eat beans and rice." Some students denied holding stereotypes, "I personally didn't have any stereotypes about the students in Mexico," claiming, instead, that others might hold them.

Post-conference reflections by MWU teacher candidates revealed that they were reconceptualizing Mexican students and their lives and showed new understanding of the other.

CCC Standard 1 was met when American students showed strengthening of cultural awareness in that they recognized their own previous lack of awareness. MWU teacher candidates were impressed that Mexican students knew their own culture well and also quite a lot about US culture. To the contrary they understood that they couldn't articulate much about their own US culture and didn't know much about Mexican culture.

CCC Standard 2 was met when MWU teacher candidates showed surprise that the Mexican students not only spoke English, but spoke it well. As one student said, "I feel stupid when considering their ability to speak two languages because I have never been able to pick up another language with that amount of skill." They were also surprised that the school facility was excellent and technically well equipped.

Meeting CCC Standard 3, MWU teacher candidates commented that the Mexican students were truly connected to the communities they served, and they admired Mexican students' pride in community, which they wished applied more to themselves and their own classmates. 
Also meeting CCC Standard 3, MWU teacher candidates were actively involved in rationally comparing systems and values of community service. We see this in the following quote, "It is rare that you can talk first-hand to students about issues they face in other countries. I liked a lot of the ideas that the [Mexican] students had for community services."

Meeting CCC Standard 4, A Perspective that is Pro-Social Justice Action, regarding their own culture, teacher candidates developed a more critical consciousness of social justice issues. MWU teacher candidates recognized some shortcomings in US school communities:

They were great intelligent kids, and I think that they are doing great things to improve their community; I just wish that more schools around here [U.S.] would get into participating in community service programs. I feel that would solve a lot of problems that we are having with students in our schools.

MWU teacher candidates attempted to construct transgenerational solutions from the Mexican experience by extrapolating this to their work as future teachers. They suggested developing similar community service programs for US schools and recommended broader application of cross-cultural communication. As one student wrote, "I think we could have a videoconference between two art classes. Students could share their art work with students from different countries."

Comanche Nation College. This inquiry-based project provided the MWU teacher candidates with a unique opportunity to self-reflect. As was hypothesized, the cultural distance between them and their Comanche partners challenged MWU teacher candidates. MWU teacher candidates were totally unfamiliar with the subject of Native American schooling. During the videoconferencing component of the project, MWU students listened intently to the presentation of Comanche culture and traditions and addressed many earnest questions to Comanche Nation College participants. The reaction papers of the MWU teacher candidates were extraordinarily self-reflective, evidencing leaps of consciousness.

MWU student reflections demonstrated that they were beginning to examine their roles as future educators and what their responsibilities were in order to be effective teachers and not perpetuate stereotypes. We found this to meet CCC Standard 4. The following student quotations capture MWU student awareness of the existence of stereotypes and prejudice:

"Teachers should ask questions to different cultural groups to learn accurate information and bring experts into the classroom to explain aspects of the history and culture."

"I also understood more about a culture I have only seen stereotypes portrayed in. I believe the videoconferencing opened my eyes most to the fact that Native Americans are more than just 
the 'cowboys and Indians' stereotypes and that their traditions still live on to this day."

"Until the videoconference, I did not realize how much I don't know about the Native American culture."

"I did not have prior knowledge to, for instance, that they have different types of nurses because they use herbal and organic substances instead of the 'antibiotics' that we simply run to a doctor and have prescribed to us."

These quotes illustrate how MWU students learned a lot about their own prejudice, learning which demonstrates how they met CCC standards 1 and 2

MWU teacher candidates also recognized the impact of their knowledge gaps on their future professional careers and on the students in their classrooms. For this reason, we found such learning to meet CCC Standard 3. One student said of this, "My constant concern about presenting such information (history) is that I am somehow trivializing it. It feels somewhat shallow to try and represent a culture with such a limited understanding, and having so much misinformation already implanted in my brain."

The open dialogue between members of the Native American academic group and the MWU students brought to the forefront issues related to cultural diversity and their own place within it. Of this, students said, "It is obvious that Americans do not give much credit to Native Americans, and this area is very personal and sensitive," and "There are so many historical facts that are hidden and replaced with 'facts' that are flattering to white Americans." This demonstrated how they met CCC Standards 2 and 4, Reduced Prejudice and A Pro-Social Justice Perspective, respectively.

Many students' reflections were particularly strong in showing a pro-social justice perspective, as valued in CCC standard 4. As one student wrote:

To stand in front of a classroom and deliver a one-sided and plainly false account of things isn't acceptable for one with such responsibility as a teacher. Race matters, and as one speaker pointed out, trying to approach a classroom color blind is not the solution. The values and beliefs of the dominant culture would be the only information transmitted, which disillusions and unfairly robs students from other ethnic groups of their identity as well as education.

In our work with the students, we saw how they made connections between social justice and educational opportunities. They projected forward how they as teachers could behave in a fashion consistent with a pro-social justice stance. They said, for example:

"Teachers need to understand the history from the peoples' perspective, and be culturally sensitive." 
"Students will want to feel free to identify with their culture while still being accepted as part of the community within the school and classroom."

"As future teachers, we should help revolutionize the teachings of Native American culture. It is about time that children start learning true facts and not how we, non-Native Americans, perceive their culture."

One student's reflection, in particular, summarizes the qualitative leap in cultural competence evidenced in most of the students' reflections: "As future teachers, it is important for us to reach out to Native American students and not act as though we are colorblind. A teacher should try to understand history from the people's perspective." This pro-social justice stance clearly illustrated CCC Standard 4.

Summary of findings on assessment of cross-cultural competencies. Our findings demonstrated for us in what ways this CCCA facilitates teacher candidates' CCC development in the course of one semester (guiding question 1), in what ways it affected their desire to take CCC into their future teaching (guiding question 2), and in what ways the thematic content of the different CCCA projects variously impacted our teacher candidates' CCC development (guiding question 3). Due to the theorized interconnectedness and recursiveness of CCC development, the presentation of our summary of findings is structured according to the three projects (as per guiding question 3 ) but in our summary we address learning related to guiding questions 1 and 2 as well.

Instead of providing case studies or simulations, these projects brought real world cross-cultural learning experiences into the classroom. The experiential learning aspect made diversity a reality, rather than a subject for passive study, and challenged students to transform themselves, that is, to develop cross-cultural competence. Each project created the opportunity for discovery about diversity and cultural identity. The learning environment was designed in such a way that students reflected on their experience and could process personal reflections collaboratively in groups. In the written papers, the students reflected on their own experience with diversity necessitating affective as well as cognitive processing.

In the Alamo project, MWU teacher candidates acknowledged that they were discarding unnamed negative stereotypes about others. They also admitted that they had been culturally encapsulated. They spoke of multiple cultural perspectives as a preferred way of knowing. The historical research and discussion enhanced MWU teacher candidates' cognitive awareness and their affective understanding of the necessity to bring multiple perspectives into the classroom.

In the community service project, several students wanted to adopt the Mexican practice in local US schools. They learned they had held biases towards 
Mexican schooling and felt propelled to counteract this in their work with future students by giving them authentic learning opportunities. More important was their willingness to be self critical about their school experiences, as well as their personal traits. An example of this was their admitting their own foreign language deficiency.

In the Comanche Nation project students encountered a worldview that was very unfamiliar to them. They reacted with respect and sadness that they had not previously known their countrymen and women. Due to the greater distance between the mainstream and Comanche culture, the MWU teacher candidates became aware of the complexity of providing and the necessity to provide authentic, meaningful cross-cultural learning experiences for their students.

In these carefully structured cross-cultural experiences, students were surprisingly open to revising prior knowledge and opinions and to moving through the psychological dissonance to positive constructive positions. The affective aspect of the experience may indeed be more important in the long term, as some of the students' comments suggested. Students recognized that crosscultural communication leads not only to deeper self-awareness but also leads to new perspectives that solve problems in one's own context. As Sperandio et al. (2010) posit about global education, in multicultural education it is vital that students make connections to their personal as well as professional lives, in their communities, and in the world at large.

The fact that the students could have these experiences in a classroom suggested to them that they, as teachers in the future, could also structure this kind of experience for their own students. "I think our class conversation with the Mexican school gave me insight I couldn't have obtained from a book," wrote one. Another student said:

The positive experience I had with videoconferencing opened my eyes to a new insight for future education.... I believe this will be a huge advantage for students and a great cultural and diverse experience, as it was for me. I am extremely excited to see this implemented into a classroom, and to also see where technology is headed and how it can tremendously benefit the students and broaden aspects of education.

Because of the way we, as researchers and teachers, were able to use the CCC standards to identify important aspects of our students' learning, we believe the CCC standards can be an effective framework for evaluating student work in a meaningful way. The CCC standards were instructive for us in recognizing and understanding the learning process of CCC. While we make this claim understanding that the findings do not show that the teacher candidates will, in fact, carry forward into their teacher lives the cross-cultural dispositions, knowledge, and skills they adopted during the projects, we firmly believe that an experience such as the one we created for our students increases the likelihood 
that CCC becomes part of a teacher candidates' orientation to future crosscultural, multicultural, and global teaching. In light of this, we feel our findings are particularly important since acknowledgement of the need for global learning is spreading throughout school systems in the United States (Obama, 2009; Reimers, 2009).

\section{Conclusion}

Our research shows that the CCCA model is adaptable to a variety of projects and topics, which develop CCC in multicultural teacher education courses in a one-semester term. What is essential is that the experiences be purposeful in engaging students in projects based on the CCC standards and that they must be situated in real-life encounters. This study also shows that the standards offer an effective evaluation framework. Additionally, our findings imply that the more distant a cross-cultural experience (see the Comanche Nation project) and the more emotionally loaded a theme (the Alamo project), the more impact there will be in the affective aspects of the standards.

We recommend that teacher education programs incorporate, at minimum, online, synchronous video experiences in a variety of teacher education courses and that these be repeated several times over the course of a degree program. Any teacher education course, be it an intervention specialist or science methods course, can incorporate a discussion with individuals from dissimilar backgrounds about relevant topics in projects designed on the basis of the four CCC standards.

We identified two areas where further research would enhance effective CCC development projects. More action research is needed to ascertain what scaffolding in CCC project design is effective in enhancing flexibility in encounters with others. At the outset we presumed that our culturally encapsulated students would be less than willing to be open to others. Yet, in our study MWU teacher candidates surprised us with the level of willingness to be positive about the differences they encountered in their communication with the other. Further research is also needed to determine developmental steps within the CCC standards in order to construct an evaluatory rubric for teachers' use. Long-term research studies will be needed to follow teacher candidates into several years of their teaching lives to trace the effects on students' crosscultural disposition of cross-culturally trained teachers. In addition, these would have to be carefully modeled studies to properly account for intervening and interacting factors.

As mentioned above, we cannot state that our teacher candidates will, in fact, carry forward into their teacher lives their cross-cultural dispositions, knowledge, and skills and become the change agents for multicultural social justice that they claimed to want to be during the projects (see also Laughling \& Nganga, 2008). This takes more coordinated work and research with our other teacher education partners. For example, teacher candidates have to be 
deliberately and continuously placed into transformative learning experiences to help them develop the longevity of a social justice aspiration. With the assistance of intentional course design and learning assessment oriented to CCC development, such as what we have modeled here, ever more diverse students will thrive in the global classroom.

\section{Notes}

1. IRB approval was obtained for the study including informed consent from the participants, stating that students were not required to participate in the study as part of earning their grade for the course.

2. In the counseling field, for example, Sue, Arredondo, and McDavis (1992) addressed cross-cultural issues early, emphasizing that engaging with others, not merely learning about them, is at the core of successful counseling.

3. The lack of sufficient broadband access on the part of international or most K12 schooling partners limited video contact.

\section{Acknowledgements}

The authors would like to acknowledge the support of the Kent State University College of Education, Health and Human Services, and the Research Fellowship grant from the Kent State University Research Center for Educational Technology. Our gratitude goes to Mayagul Satlykgylyjova for editing assistance.

\section{References}

American Council on Education. (2006). Handbook for advancing comprehensive internationalization. Washington, DC: ACE.

Association of American Colleges and Universities. (1999). Liberal education and global citizenship: The arts of democracy. Washington, DC: Association of American Colleges and Universities.

Allport, G. (1954,1979). The nature of prejudice. Cambridge, MA: Addison Wesley.

Banks, J.A. (1988). Multiethnic education: Theory and practice $\left(2^{\text {nd }}\right.$ ed.). Boston: Allyn and Bacon.

Banks, J.A. (2004). Introduction: Democratic citizenship education in multicultural societies. In J. A. Banks (Ed.), Diversity and citizenship education: Global perspectives (pp. 3-15). San Francisco, CA: Jossey-Bass. 
Barone, T., \& Eisner, E. (2006). Arts-based educational research. In G. C. Green \& P. Elmore (Eds.), Complementary methods in research in education (pp. 95-109). Mahwah, NJ: Lawrence Erlbaum Associates.

Bennet, C. I. (1999). Comprehensive multicultural education. Boston, MA: Allyn and Bacon.

Bennett, M. J. (1993). Towards ethno-relativism: A developmental model of intercultural sensitivity. In R. M. Paige (Ed.), Education for the intercultural experience (pp. 21-71). Yarmouth, ME: Intercultural Press.

Bennett, M. J. (2009). Defining measuring and facilitating intercultural learning: A conceptual introduction to the intercultural education double supplement. Intercultural Education, 20( S1), 1-13. doi: 10.1080/14675980903370763

Bennett, J. M., \& Bennett, M. J. (2004). Developing intercultural sensitivity, an integrative approach to global and domestic diversity. In D. Landis (Ed.), Handbook of intercultural training (pp.147-165). Beverly Hills, CA: Sage Publications.

Braskamp, L. B., Braskamp, D. C., \& Merrill, K. C. (2010). Global perspectives inventory (GPl): Its purpose, construction, potential uses, and psychometric characteristics. Chicago, IL: Global Perspective Institute.

Brislin, R. W., Cushner, K., Cherrie, C., \& Yong, M. (1986). Intercultural interactions: A practical guide. Beverly Hills, CA: Sage Publications.

Burbules, N. C. (2000). Does the internet constitute a global educational community? In R. Arnove \& C.A. Torres (Eds.), Globalization and education: Critical perspectives (pp. 323-357). New York, NY: Routledge.

Burbules, N. C., \& Rice. S. (2000). Dialogue across differences: Continuing the conversation. In E. M. Duarte \& S. Smith (Eds.), Foundational perspectives in multicultural education (pp. 247-273). New York, NY: Longman.

Casteel, J. D. (1976). Cross-cultural models of teaching. Gainesville, FL: University of Florida Press.

Cross, W. E., Strauss, L., \& Fhagen-Smith, P. (1999). African American identity development across the life span: Educational implications. In R. H. Sheets \& E. R. Hollins (Eds.), Racial and ethnic identity in school practices: Aspects of human development (pp. 29-47). Mahwah, NJ: Erlbaum.

Cushner, K., \& Brennan, S. (Eds.) (2007). Intercultural student teaching: A bridge to global competence. Lanham, MD: Rowman \& Littleton Education.

Delpit, L. D. (1988). The silenced dialogue: Power and pedagogy in educating other people's children. Harvard Educational Review, 58(3), 280-298.

Derman-Sparks, L., \& Brunson Phillips, C. B. (1997). Teaching/learning antiracism: A developmental approach. New York, NY: Teachers College Press. 
Diller, J., \& Moule, J. (2005). Cultural competence: A primer for educators. Belmont, CA: Thomson Wadsworth.

Fiske, S., \& Taylor, S. (1992). Social cognition. New York, NY: McGraw-Hill.

Fulton, K., \& Riel, M. (1999). Professional development through learning communities. EDUTOPIA Online. Retrieved from http://glef.org/

Gay, G. (2000). Culturally responsive teaching: Theory, research, and practice. New York, NY: Teachers College Press.

Gay, G. (2001). Curriculum theory and multicultural education. In J. A. Banks \& C. A. McGee Banks (Eds.), Handbook of research on multicultural education (pp. 25-43). San Francisco, CA: Jossey-Bass Publishers.

Gudykunst, W. H. B., \& Kim, Y. Y. (1984). Communication with strangers: An approach to cross-cultural communication. Reading, MA: Addison-Wesley.

Hanvey, R. (1976). An attainable global perspective. The American Forum for Global Education. Retrieved from http://www.globaled.org/an_att_glob_ persp_04_11_29.pdf

Harris, J. (2000). Structuring internet-enriched learning spaces for understanding and action. Learning and Leading with Technology, 28(4). Retrieved from http:///www.iste.org/

Helms, J. E. (1997). Toward a model of white racial identity development. In D. Arnold \& J. E. King (Eds.), College student development and academic life: Psychological, intellectual, social and moral issues (pp.49-66). New York, NY: Garland Publishing.

Hollins, E. R. (1999). Relating ethnic and racial identity development to teaching. In R. H. Sheets \& E. R. Hollins (Eds.), Racial and ethnic identity in school practices: Aspects of human development (pp.183-194). Mahwah, NJ: Erlbaum.

Jackson, A. (2009). Global competence: The knowledge and skills our students need. In Asia Society. Retrieved from http://asiasociety.org/education/ partnership-global-learning/making-case/global-competence-prepareyouth-engage-world

Jonassen, D. H. (2000). Computers as mindtools in schools: Engaging critical thinking. Upper Saddle River, NJ: Merrill/Prentice Hall.

Jonassen, D. H., Hjowland, J., Moore, J., \& Marra, R. M. (2003). Learning to solve problems with technology, a constructivist perspective $\left(2^{\text {nd }} \mathrm{ed}\right)$. Upper Saddle River, NJ: Merrill Prentice Hall.

Kelley, C., \& Meyers, J. (1987, 1989, 1992, 1995). Cross-cultural adaptability inventory manual. Minneapolis, MN: Yarmouth, ME: Intercultural Press and Pearson Reid London House.

Laughlin, P., \& Nganga, L. (2008). Interdisciplinary ways of knowing: A collaborative teacher education project for culturally responsive pedagogy 
in rural white America. Spaces for Difference: An Interdisciplinary Journal, 1(2). Retrieved from http://escholarship.ucop.edu/uc/item/6t08f2m4

Ladson-Billings, G. (1995). But that's just good teaching! The case for culturally relevant pedagogy. Theory into Practice, 34(3), 159-165.

Mansilla, V.B., \& Jackson, A. (2011). Educating for global competence: Preparing our youth to engage the world. Council of Chief State School Officers' EdSteps Initiative \& Asia Society Partnership for Global Learning. Retrieved from http://www.ccsso.org/Resources/Publications/Educating_ for_Global_Competence.html

Merrifield, M., Lo, J., Sum, P., \& Kasai M. (2008). Worldmindedness: Taking off the blinders. Journal of Curriculum and Instruction, 2(1). Retrieved from http://www.joci.ecu.edu/index.php/JoCl/article/viewFile/9/12

Merrifield, M. (2005). Educating teachers for a global age. Presentation at the Ohio Regional NAME conference. Retrieved from http://teachglobaled.net

Merrifield, M. (2001). Pedagogy for global perspectives in education. In P. O'Meara, H. Mehlinger, \& R.M. Newman (Eds.), Changing perspectives on international education (pp. 309-30). Bloomington, IN: Indiana University Press.

Nieto, S. (2000). Affirming diversity: The sociopolitical context of multicultural education ( $3^{\text {rd }}$ ed). New York, NY: Longman.

Newman, F. M., \& Wehlage, G. G. (1993). Five standards of authentic instruction. Educational Leadership, 50(7), 8-12.

Obama, B. (2009). President Obama calls for American education system to align with global economy. Pennsylvania Crier. Retrieved from http://www.pennsylvaniacrier.com/filemgmt_data/files/President\%200bam a\%20Calls\%20for\%20American\%20Education\%20System\%20to\%20Alig n\%20with\%20Global\%20Economy.pdf

Ponterotto, J. G., \& Pederson, P. B. (1993). Preventive prejudice: A guide for counselors and educators. Newbury Park, CA: Sage.

Phinney, J. S. (1992). The multigroup ethnic identity measure: A new scale for use with diverse groups. Journal of Adolescent Research, 7, 156-176. doi: 10.1177/074355489272003

Reimers, F. (January, 2009). Global competency is imperative for global success. Chronicle of Higher Education, 55(21), A29. Retrieved from http://chronicle.com/article/Global-Competency-Is/9742

Scarboro, D. (2012). Interview in Clydesdale, H. Global Vision: Education aligns to a new world order. Asia Society. Retrieved from http://asiasociety.org/ education/chinese-language-initiatives/global-vision-education-aligns-newworld-order

Scardamalia, M., Bereiter, C., \& Lamon, D. (1994). The CSILE Project: Trying to bring the classroom into the world. In K. McGilly (Ed.), Classroom lessons: 
Integrating cognitive theory and classroom practice (pp. 201-228). Cambridge, MA: MIT Press.

Sleeter, C. E. (1991). Empowerment through multicultural education. Albany, NY: State University of New York Press.

Sleeter, C., \& Grant, C. (1987). An analysis of multicultural education in the United States. Harvard Educational Review, 7, 421-444.

Sperandio, J., Grudzinski-Hall, M., \& Stewart-Gambino. H. (2010). Developing an undergraduate global citizenship program: Challenges of definition and assessment. International Journal of Teaching and Learning in Higher Education, 22(1), 12-22.

Stewart, V. (2007). Becoming citizens of the world. Educational Leadership, 64(7), 8-14.

Sue, D. W., Arrendondo, P., \& McDavis, R.J. (1992). Multicultural counseling competencies and standards: A call for the profession. Journal of Counseling and Development, 70, 477-486.

Villegas, A. M., \& Lucas, T., (2002). Preparing culturally responsive teachers: Rethinking the curriculum. Journal of Teacher Education, 3(1), 20-22. 